Research Article

\title{
Effectiveness of pulse oximetry screening for congenital heart disease in asymptomatic new-borns
}

\author{
Audil Mohmad Lanker ${ }^{1}$, Javed Chowdhary ${ }^{1}$, Nasir Jeelani ${ }^{1}$, \\ Shazia Jeelani $^{2}$, Ashfaq Ul Hassan ${ }^{3}$, Nasir-ud-din Wani ${ }^{4}$
}

\author{
${ }^{1}$ Department of Pediatrics, Government Medical College, Srinagar, J \& K, India \\ ${ }^{2}$ MBBS, Government Medical College, Srinagar, J \& K, India \\ ${ }^{3}$ Department of Anatomy, SKIMS Medical College, Bemina, J \& K, India \\ ${ }^{4}$ Department of CVTS, SKIMS, Soura, Srinagar, J \& K, India
}

Received: 9 July 2014

Accepted: 20 July 2014

\section{*Correspondence:}

Dr. Ashfaq Ul Hassan,

E-mail: ashhassan@ rediffmail.com

(C) 2014 Lanker AM et al. This is an open-access article distributed under the terms of the Creative Commons Attribution Non-Commercial License, which permits unrestricted non-commercial use, distribution, and reproduction in any medium, provided the original work is properly cited.

\section{ABSTRACT}

Background: Congenital Cardio-Vascular Malformations (CCVMs) are relatively common with a prevalence of 5-10 in every 1000 live births. CCVM represents a new-born condition that would be ideally suited to a screening program if simple and reliable methods were available. Pulse oximetry has been proposed as a screening method for the detection of congenital heart defects.

Methods: Hospital based prospective non-randomized study conducted over a period of one year at the department of pediatrics in G.B. Panth hospital (Neonatology) and L.D. hospital (Neonatology). A total of 1200 asymptomatic newborns attending G.B. Panth, neonatology/L.D. neonatology were screened with pulse oximetry. Oximetric screening for CCVM was performed by obtaining a single determination of postductal saturation at $>24$ hours. All new-borns underwent additional evaluation by echocardiography.

Results: Out of 1200 newborns screened three had postductal saturation $\leq 95 \%$. Echocardiography revealed TGA (transposition of great vessels) in one; TA (truncus arteriosus) in other and third one had structurally normal heart on echocardiography. There was one false negative screen (found in the inpatient records of G.B. Panth hospital). The sensitivity, specificity, positive predictive value and negative predictive value of pulse oximetry in screening for CCVM in asymptomatic new-borns was found to be $66.67 \%, 99.9 \%, 66.67 \%$ and $99.9 \%$ respectively.

Conclusion: This screening test is simple, non-invasive and inexpensive. The sensitivity, specificity, and predictive value in this population were satisfactory, indicating that screening should be applied to larger populations, particularly in developing countries where lower rates of detection result in increased CCVM prevalence in asymptomatic new-borns.

Keywords: Pulse, Congenital, Oxygen, Vascular, Malformation

\section{INTRODUCTION}

Congenital Cardio-Vascular Malformations (CCVMs) are relatively common with a prevalence of 5-10 in every 1000 live births. ${ }^{1}$ With improvements in diagnosis and treatment, the outlook for new-borns with CCVMs has changed considerably, but these malformations still contribute to significant morbidity and mortality in this age group. Children with CCVM are at approximately two times higher risk of mortality in first year of life. ${ }^{2}$ Several life threatening CCVMs are not recognized with screening level II obstetrical ultrasound ${ }^{3,4}$ or clinically 
apparent in the early new-born period. Routine neonatal examination fails to detect $>50 \%$ of infants with $\mathrm{CCVM}^{5}{ }^{5}$

Most new-borns with Critical Congenital Heart Disease (CCHD) can be diagnosed by echocardiography, palliated with prostaglandin infusion, and treated with surgery or transcatheter interventions. In the current era, congenital heart surgery allows for repair or palliation of nearly all types of congenital heart malformations. Congenital heart surgery, together with transcatheter interventions, has resulted in a marked improvement in survival for those with CCHD. ${ }^{6}$

Intervention is typically performed in the first weeks of life to optimize hemodynamics and prevent end-organ injury associated with delayed diagnosis. Because timely recognition of congenital heart malformations could improve outcomes, it is important to identify and evaluate strategies to enhance early detection. Pulse oximetry has been proposed as one such strategy, and legislation has been proposed to support this practice. ${ }^{7}$

Oximetric screening for CCVM seems to satisfy the requirements for a screening test: 1) the prevalence of CCVM among asymptomatic new-borns is high, particularly in areas with lower rates of fetal echocardiography; 2) the technique of oximetric screening is simple and reliable, 3) effective cardiovascular interventions are available, and 4) the cost/benefit ratio of this screening test is favorable. No costs were incurred for equipment, supplies, or personnel, and two asymptomatic new-borns were prevented from going home with undiagnosed CCVM.

\section{METHODS}

\section{Design}

Hospital-based, cross sectional study from August 2010 to July 2011.

\section{Settings}

The study was conducted at department of paediatrics in L.D. hospital (Neonatology ward) - hospital A and G.B. Panth hospital (Neonatology ward) - hospital B, with the catchment area of both rural and urban populations.

Both these hospitals are tertiary care hospitals associated with government medical college, Srinagar, Kashmir.

\section{Inclusion criteria}

All asymptomatic new-borns attending G.B. Panth, neonatology/L.D. neonatology who did not manifest cyanosis, tachypnea (respiratory rate $>60 / \mathrm{min}$ ), grunting, flaring, retractions, murmur, active precordium, or diminished pulses were screened with pulse oximetry.

\section{Approach}

Oximetric screening for congenital cardiovascular malformations was performed by obtaining a single determination of post-ductal saturation on all asymptomatic new-borns that fulfilled the inclusion criteria.

Nelcor oximax pulse oximeter was used to determine post-ductal saturation. The probe was placed over left foot. To ensure universal screening, the timing of oximetric determination was $>24$ hours age. All these new-borns underwent additional evaluation by echocardiography which is considered as gold standard. Data regarding true and false positives as well as negatives was collected and sensitivity, specificity and predictive values of pulse oximetry screening of asymptomatic new-borns for CCVM were determined.

\section{Statistical calculations}

True positives were defined as those new-borns who were screened with pulse oximetry with $\mathrm{SpO}_{2} \leq 95 \%$ and, echocardiography revealed a congenital heart disease.

True negatives were defined as those new-borns who were screened with pulse oximetry with $\mathrm{SpO}_{2}>95 \%$ and, echocardiography revealed structurally normal heart.

False positives were defined as those new-borns who were screened with pulse oximetry with $\mathrm{SpO}_{2} \leq 95 \%$, but echocardiography revealed structurally normal heart.

False negatives were defined as those new-borns who were screened with pulse oximetry with $\mathrm{SpO}_{2}>95 \%$, but echocardiography revealed a congenital heart disease.

\section{RESULTS}

A cross sectional study was conducted on all asymptomatic newborns attending the neonatology ward of hospital A and hospital B comprising 940 and 260 newborns respectively.

Table 1: Study group characteristics.

\begin{tabular}{|ll|}
\hline Characteristics & $638(53.2 \%)$ \\
\hline Male & $562(46.8 \%)$ \\
\hline Female & 881 \\
\hline Sex ratio & $60.3 \%$ \\
\hline Rural population & $39.7 \%$ \\
\hline Urban population & $4.4 \%$ of new-borns. \\
\hline History of consanguinity & 11 new-borns $(0.9 \%)$. \\
\hline Family history of CHD & $39-40$ weeks. \\
\hline $\begin{array}{l}\text { Median gestational age of } \\
\text { the study group }\end{array}$ & $>24$ hours \\
\hline Mean age at screening & $>95 \%$ \\
\hline $\begin{array}{l}\text { Normal cut-off value for } \\
\text { post-ductal saturation }\end{array}$ & \\
\hline
\end{tabular}


Various epidemiological parameters obtained in the study group are summarized in Table 1 .

A single determination of post-ductal saturation was obtained on all asymptomatic new-borns at $\geq 24$ hours of age. All new-borns underwent additional evaluation by echocardiography.
Out of 1200 asymptomatic neonates, post-ductal desaturation $\left(\mathrm{PO}_{2} \leq 95 \%\right)$ was seen in only three (Table 2). Echocardiography revealed Transposition of Great Vessels (TGA) in one Truncus Arteriosus (TA) in other and third one had structurally normal heart on echocardiography (false positive).

Table 2: Distribution of cases according to post-ductal saturation.

\begin{tabular}{|c|c|c|c|c|c|c|c|}
\hline & \multicolumn{6}{|c|}{ Post-ductal saturation } & \multirow{2}{*}{ Tota } \\
\hline & $\leq 95 \%$ & $96 \%$ & $97 \%$ & $98 \%$ & $99 \%$ & $100 \%$ & \\
\hline Hospital A & 3 & 271 & 246 & 335 & 69 & 16 & \multirow{2}{*}{940} \\
\hline \%age & $0.3 \%$ & $28.8 \%$ & $26.5 \%$ & $35.6 \%$ & $7.3 \%$ & $1.7 \%$ & \\
\hline Hospital B & 0 & 68 & 62 & 80 & 41 & 9 & \multirow{2}{*}{260} \\
\hline$\%$ age & $0 \%$ & $26.2 \%$ & $23.8 \%$ & $30.8 \%$ & $15.8 \%$ & $3.5 \%$ & \\
\hline Total & 3 & 339 & 308 & 415 & 110 & 25 & \multirow{2}{*}{1200} \\
\hline \%age & $0.3 \%$ & $28.2 \%$ & $25.6 \%$ & $34.6 \%$ & $9.2 \%$ & $2.1 \%$ & \\
\hline
\end{tabular}

One false negative screen having dextro transposition of great arteries with ventricular septal defect (dTGA + VSD) was found on echocardiography in hospital B.

Various statistical parameters obtained are summarised in Table 3.

Table 3: Statistical parameters obtained in the study group.

\begin{tabular}{|ll|}
\hline Statistical parameters \\
\hline True positive & 2 \\
\hline False positive & 1 \\
\hline False positive rate & 0.08 \\
\hline False negative & 1 \\
\hline True negative & 1196 \\
\hline Positive predictive value & $66.67 \%$ \\
\hline Negative predictive value & $99.90 \%$ \\
\hline Sensitivity & $66.67 \%$ \\
\hline Specificity & $99.90 \%$ \\
\hline
\end{tabular}

Therefore, 1 in 600 asymptomatic newborns was found to have a CCVM by oximetric screening before discharge.

There was no accrued cost as reusable oximeter probes were used with oximeters already in place in the neonatology wards.

\section{DISCUSSION}

Congenital heart defects are the most common group of congenital malformations. Early detection of major congenital heart defects (i.e.; those leading to death or requiring invasive intervention before 1 year of age) might improve the outcome of new-born babies. ${ }^{8}$
Improvement with early detection is particularly true for critical, duct-dependent lesions in which closure of the ductus arteriosus can result in acute cardiovascular collapse, acidosis, and death. ${ }^{9-11}$ Screening for congenital heart defects relies on mid-trimester ultrasound scan in which the fetal heart chambers are imaged, and postnatal physical examination that includes assessment of pulses and heart sounds and inspection for cyanosis. Both screening methods have a fairly low detection rate and a substantial number of babies are discharged from hospital before congenital heart defects are diagnosed. ${ }^{5,12-15}$ Some of these babies die or present in such a poor clinical state that the outcome, despite treatment, is compromised.

Pulse oximetry is a well-established, accurate, noninvasive test for objective quantification of hypoxaemia. Use of this screening method for early detection of congenital heart defects is based on the rationale that clinically undetectable hypoxaemia is present, to some degree, in most potentially life-threatening cases. Pulse oximetry has been assessed as a screening method for congenital heart defects in new-born babies in many studies. $^{16-26}$

Out of 1200 asymptomatic newborns screened by pulse oximetry only 3 cases were found to have $\mathrm{SPO}_{2} \leq 95 \%$. These 3 cases further underwent echocardiography to confirm the findings of screening test. 2 out of 3 cases were detected to have CCVM. Thus, prevalence of CCVM in asymptomatic newborns was found to be 1 in $600(0.16 \%)$. Our results were comparable with those obtained by Tautzet al. ${ }^{27}$ and Arlettaz et al. ${ }^{23}$

Tautzet al. ${ }^{27}$ found that CCVM was identified using pulse oximetric screening in 1 in 1000 asymptomatic newborns $(0.1 \%)$. Another study conducted by Arlettaz and 
collegues $^{23}$ in 3262 newborns found that there were 11 cases of CCVM in asymptomatic neonates with $\mathrm{SPO}_{2}$ $<95 \%$ giving the prevalence of 1 in 297 (0.33\%).

The sensitivity was found to be $66.67 \%$ which is comparable to the results obtained by Koppel et al. ${ }^{19}$, Bakr et al. ${ }^{22}$, Rosati et al. ${ }^{21}$ and Richmond et al. ${ }^{17}$ (60.0\%, $60.0 \%, 66.7 \%$ and $69.2 \%$ respectively). Nine out of ten studies in a review by Mahle et al. ${ }^{28}$ found sensitivities to be less than $90 \%$, ranging from $0 \%$ to $87 \%$. This is explained in part by the fact that hypoxemia is not present in some forms of CCHD.

The specificity was found to be $99.9 \%$ which is again comparable to the studies conducted by other workers. $^{17,19,22}$

The positive predictive value of $66.67 \%$ was comparable to that obtained by Rosati et al. ${ }^{21}$ who obtained a PPV of $66.7 \%$. However, it is less than that obtained by most of the other workers like Koppel et al., ${ }^{19}$ Arlettaz et al. ${ }^{23}$ and others but more than that obtained by Richmond et al. ${ }^{17}$ and Hoke et al. ${ }^{16}$

The negative predictive value of $99.9 \%$ is comparable to all other studies which have reported it to be between $98 \%$ to $100 \%$. $^{16-19,21-23}$

The false positive rate was found to be $0.08 \%$ and was comparable to that obtained by Reich et al. ${ }^{18}$ who reported it to be $0.09 \%$ at $>24$ hours. A low false positive rate reduces the number of unnecessary echocardiograms.

\section{Limitations of the study}

1. The sample size is relatively small and makes the calculation of effectiveness of pulse oximetry screening relatively difficult.

2. We assumed that all the diagnosis were to be made at G.B. Panth and L.D. hospital; we could, however, have missed a small number of infants diagnosed elsewhere.

\section{CONCLUSION}

Pulse oximetry is a safe, non-invasive, feasible, and reasonably accurate test, which has a sensitivity that is better than that of antenatal screening and clinical examination.

- It adds value to existing screening procedures and is likely to be useful for identification of cases of critical congenital heart defects that would otherwise go undetected.

- The detection of other diseases such as significant congenital heart defects, and respiratory and infective illnesses is an additional advantage.
- The results of this study agree with the strong evidence that indicates the potential benefits of the introduction of pre-discharge pulse oximetry screening as a routine procedure.

To conclude, various studies and review articles all over the globe have suggested the usefulness of pulse oximetry screening for detecting the congenital cardio vascular malformations in asymptomatic new-borns. However, very little research has been done in this particular field in our country. This study adds to the evidence in support of starting the pulse oximetry as a routine neonatal screening programme to let many a children to live a long life with healthy hearts.

Funding: No funding sources

Conflict of interest: None declared

Ethical approval: The study was approved by the institutional ethics committee

\section{REFERENCES}

1. Payne RM, Johnson MC, Grant JW, Strauss AW. Toward a molecular understanding of congenital heart disease. Circulation. 1995;91:494-504.

2. Druschel C, Hughes JP, Olsen C. Mortality among infants with congenital malformations in New York State, 1983-1988. Publ Health Rep. 1996;111:35965.

3. Sharland G. Changing impact of fetal diagnosis of congenital heart disease. Arch Dis Child. 1997;77:F1-3.

4. Fernandez CO, Ramaciotti C, Martin LB, Twickler DM. The four chamber view and its sensitivity in detecting congenital heart defects. Cardiology. 1998;90:202-6.

5. Wren C, Richmond S, Donaldson L. Presentation of congenital heart disease in infancy: implications for routine examination. Arch Dis Child Fetal Neonatal Ed. 1999;80: F49-53.

6. Boneva RS, Botto LD, Moore CA, Yang Q, Correa A, Erickson JD. Mortality associated with congenital heart defects in the United States: trends and racial disparities, 1979-1997. Circulation. 2001;103:2376-81.

7. Mississippi 2005 Regular Session. House bill No. 1052, 2005. Available at: http://billstatus.ls.state.ms.us/documents/2005/pdf/H B/1000-1099/HB1052IN.pdf.

8. Brown KL, Ridout DA, Hoskote A, Verhulst L, Ricci M, Bull C. Delayed diagnosis of congenital heart disease worsens preoperative condition and outcome of surgery in neonates. Heart. 2006;92:1298-302.

9. Brown JW, Park HJ, Turrentine MW. Arterial switch operation: factors impacting survival in the current era. Ann Thorac Surg. 2001;71:1978-84.

10. Franklin O, Burch M, Manning N, Sleeman K, Gould S, Archer N. Prenatal diagnosis of 
coarctation of the aorta improves survival and reduces morbidity. Heart. 2002; 87: 67-9.

11. Tworetsky W, McElhinney DB, Reddy VM, Brook MM, Hanley FL, Silverman NH. Improved surgical outcome after fetal diagnosis of hypoplastic left heart syndrome. Circulation. 2001;103:1269-73.

12. Cartlidge PH. Routine discharge examination of babies: is it necessary? Arch Dis Child. 1992;67:1421-2.

13. Bull $\mathrm{C}$, for the British Paediatric Cardiac Association. Current and potential impact of fetal diagnosis on prevalence and spectrum of serious congenital heart disease at term in the UK. Lancet. 1999;354:1242-7.

14. Tegnander E, Williams W, Johansen OJ, Blaas HGK, Eik-Nes SH. Prenatal detection of heart defects in a non-selected population of 30149 fetuses detection rates and outcomes. Ultrasound Obstet Gynecol. 2006;27:252-65.

15. Garne E, Stoll C, Clementi M, the Euroscan Group. Evaluation of prenatal diagnosis of congenital heart diseases by ultrasound: experience from 20 European registries. Ultrasound Obstet Gynecol. 2001;17:386-91.

16. Hoke TR, Donohue PK, Bawa PK, Mitchell RD, Pathak A, Rowe PC, et al. Oxygen saturation as a screening test for critical congenital heart disease: a preliminary study. Pediatr Cardiol. 2002;23:403-9.

17. Richmond S, Reay G, Abu Harb M. Routine pulse oximetry in the asymptomatic new-born. Arch Dis Child Fetal Neonatal Ed. 2002;87:F83-8.

18. Reich JD, Miller S, Brogdon B, Casatelli J, Gompf TC, Huhta JC, et al. The use of pulse oximetry to detect congenital heart disease. J Pediatr. 2003;142:268-72.

19. Koppel RI, Druschel CM, Carter T, Goldberg BE, Mehta PN, Talwar R, et al. Effectiveness of pulse oximetry screening for congenital heart disease in asymptomatic new-borns. Pediatrics. 2003 Mar;111(3):760-1.

20. de Wahl Granelli A, Mellander M, Sunnegardh J, Sandberg K, Ostman-Smith I. Screening for ductdependant congenital heart disease with pulse oximetry: a critical evaluation of strategies to maximize sensitivity. Acta Paediatr. 2005;94:15906.

21. Rosati E, Chitano G, Dipaola L, De Felice C, Latini G. Indications and limitations for a neonatal pulse oximetry screening of critical congenital heart disease. J Perinat Med. 2005;33:455-7.

22. Bakr AF, Habib HS. Combining pulse oximetry and clinical examination in screening for congenital heart disease. Pediatr Cardiol. 2005;26:832-5.

23. Arlettaz R, Bauschatz AS, Monkhoff M, Essers B, Bauersfeld $U$. The contribution of pulse oximetry to the early detection of congenital heart disease in new-borns. Eur J Pediatr. 2006;165:94-8.

24. Meberg A, Brügmann-Pieper S, Due R Jr, Eskedal L, Fagerli I, Farstad T, et al. First day of life pulse oximetry screening to detect congenital heart defects. J Pediatr. 2008;152:761-5.

25. Sendelbach DM, Lai S, Jackson GJ, Fixler D, Stehel EK, Engle WD. Pulse oximetry (POx) screening of term and late pre-term neonates at 4 hours postnatal (PN) to detect cyanotic congenital heart disease (CCHD). Presented at: Honolulu, Hawaii: Pediatric Academic Societics; May 2-6, 2008. Abstract EPAS2008:5896.2.

26. Riede FT, Wörner C, Dähnert I, Möckel A, Kostelka M, Schneider P. Effectiveness of neonatal pulse oximetry screening for detection of critical congenital heart disease in daily clinical routine: results from a prospective multicenter study. Eur J Pediatr. 2010 Aug;169(8):975-81.

27. Tautz J, Merkel C, Loersch F, Egen O, Hagele F, Thon HM, et al. Implication of pulse oxymetry screening for detection of congenital heart defects. Klin Pediatr. 2010 Sep;222(5):291-5.

28. Mahle WT, Newburger JW, Matherne GP, Smith FC, Hoke TR, Koppel R, et al. Role of pulse oximetry in examining new-borns for congenital heart disease: a scientific statement from AHA and AAP. Pediatrics. 2009 Aug;124(2):823-36.

DOI: $10.5455 / 2320-6012 . i j r m s 20140894$

Cite this article as: Lanker AM, Chowdhary J, Jeelani N, Jeelani S, Hassan AU, Wani N. Effectiveness of pulse oximetry screening for congenital heart disease in asymptomatic new-borns. Int J Res Med Sci 2014;2:1112-6. 